\title{
Comparative Analysis of Manufacturing and Logistics Linkage Development and Logistics Outsourcing
}

\author{
LIU Yongsheng ${ }^{1, a}$ CHENG Yindi ${ }^{2, b}$ \\ ${ }^{1,2}$ Beijing Wuzi University, Beijing, China, 101149 \\ aE-mail:bjwylys@sina.com b907144552@qq.com
}

Keyword: logistics outsourcing; linkage development ; comparative analysis

\begin{abstract}
Manufacturing and logistics linkage development has caused widespread concern and active practice in the industry. Whether in theory or in practice, however, a lot of people simply understand manufacturing and logistics linkage as logistics outsourcing, which will restrict the linkage development of manufacturing and logistics to a certain extent. This paper started from the basic concept, by comparative analysis to the background and problems, purpose, requirements, relationship and the research content, elaborated the similarities and differences between manufacturing and logistics industries linkage development and logistics outsourcing, in order to have a more comprehensive understanding of two industries linkage development.
\end{abstract}

\section{Introduction}

"Twelfth Five-Year Plan" makes the manufacturing and logistics linkage development become a topic of great concern once again. Governments at all levels actively promote the development and some industries in efforts to implement the linkage development, at the same time, the academic circle actively explore the necessity, mode, existing problems and strategies in linkage development. However, in the research on manufacturing and logistics linkage development, few people concerned about the true essence of linkage development, and even some industrialists and scholars treat the two industry linkage as the enterprise logistics outsourcing, then what is the true essence of two industry linkage? Does it have any relationship with the enterprise logistics outsourcing? To clarify these issues is of great significance to promote the linkage development of China's manufacturing industry and logistics industry.

Logistics outsourcing is a management model that enterprise integrates external resources, entrusts its logistics business to other professional operation company, in order to achieve lower costs, improve efficiency, give full play to its core-competitiveness.[1] It's a effective mean to improve material flow speed, save logistics cost and reduce backlog of funds in float. While linkage, originally refers to related things, one moves leading others also followed the movement, namely joint action. So the two industries linkage should mean that once one of manufacturing enterprises and logistics enterprises changes the other follows. So the two industries linkage development can be understood as Collaborative activity that manufacturing enterprises and logistics enterprises are deeply involved in the other's process of management, organization, planning, operation, control, so as to pursuit resources intensive management and enterprise overall optimization. The linkage development and logistics outsourcing have in common, but they can't be equated.

\section{Background and Problems}

The logistics outsourcing was proposed early than linkage development, but they are both not mature. No matter the manufacturing enterprise in two industry linkage or the commissioning party in logistics outsourcing are feel worried about logistics enterprises in the supply of services, and unfamiliar to logistics enterprises, So they used more self-conducting logistics mode, with low efficiency and high cost, and caused by a lack of overall logistics demand in market. On the other hand, the logistics industry in China started late, and its development is not mature. The strategic considerations and ability that logistics enterprises are deeply involved in manufacturing lacking, so the overall level of service is low, which can't promote the development of manufacturing industry, 
and become a bottleneck restricting the development of the manufacturing industry, leading to the relatively low level and slow development of logistics outsourcing in China.

In the aspect of policy system, although the government attitude to the enterprise logistics outsourcing and the two industry linkage are encouraging, the two are facing some loopholes in the policy. For example, the double taxation and heavy tax burden in the financing credit, land using and other aspects, implementation of land and other preferential policies is not in place, the lack of motivation for logistics business separation and outsourcing, etc.. In this context, manufacturing enterprises and logistics enterprises are facing new opportunities, but more challenges, thus accelerating transformation of the pattern of development is more and more urgent.

The problems that linkage development and logistics outsourcing are facing are similar, but the background is different. Compared with the two industry linkage development, the enterprise logistics outsourcing concept was introduced earlier in China. The exploration on enterprise logistics outsourcing and professional service began in the late nineties in twentieth century, and in recent years, with the rapid development of the third party logistics enterprise, the concept of outsourcing are more and more mature, there have been more and more enterprises to entrust their logistics business to the third party logistics company to complete. However, China's logistics outsourcing market is not yet totally mature, and the relationship between supply and demand is very unstable, and most outsourcing is a trading relationship based on complementary needs. "Sixth China logistics Supply and demand situation survey report" [2]shows that Logistics outsourcing of domestic manufacturing enterprises are still concentrated on the transportation, storage and other traditional project, and cooperation level is not high. In the logistics outsourcing market, the client is in active and dominant position, while the logistics as a service provider, in a passive subordinate status in a certain extent. The clients pursue a lower price blindly through the bidding or negotiation, while logistics service providers can only reduce the cost, so both sides come into competitive relationship, rather than strategic cooperative relationship. In addition, the two parties can't share information and resource, and can't achieve the win-win effect. [3]

In two industry linkage the client is the manufacturing industry, while China is a big manufacturing country, so the logistics demand of manufacturing industry is far greater than other industries. According to the statistics of China Logistics Information Center, the total social logistics costs still maintain a rapid growth 1 to November in 2011, in which the industrial logistics is 132.8 trillion yuan, accounting for $90.8 \%$ in the total social logistics. This figure shows the logistics volume in linkage is very large. The two industry linkage has an important influence on the macro economy, so the function of the government on the two industry linkage is more obvious than the enterprise logistics outsourcing, and all levels of government pay great attention. some provinces and cities have set up leading group, made clear leading department, and in some areas the division, policy measures, promote scheme has initially formed. In September 25, 2007, the national development and Reform Commission organized the first meeting of national linkage development of manufacturing and logistics industry in Shanghai, and officially launched the two industry linkage development. In March 13, 2009, the State Council officially issued the specific content of the "logistics industry restructuring and revitalization plan". The plan put the "linkage development of manufacturing and logistics" in the list of the nine major projects planning. The "Plan" encourages the linkage development of manufacturing and logistics industry definitely, so as to release the demand, and promote the interactive development of logistics enterprises and production enterprises. [4] The loopholes such as repeated tax policy still affect the linkage development, but the government's policy adjustment and encourage methods gradually strengthen, manufacturing and logistics industry will usher in the golden period of development.

\section{Objective}

There are multiple objective and significance in the two industry linkage development and enterprise logistics outsourcing, and the main purpose is concentrating the limited resources on the core business in the situation that enterprise resources is limited. Namely enterprises grasp the part of business knowledge and technology-dependent and high value-added in their own hands, while 
put the other low value-added part to the third party logistics to complete. Besides, the two can achieve risk-sharing between the principal and the supplier, thus effectively reducing enterprise risk. In addition, the logistics infrastructure investment is comparative large, while the linkage development of two industry and logistics outsourcing both can greatly reduce or completely savings the investment in logistics facilities, equipment, logistics personnel salary, training costs and other soft or hardware investment, to save investment cost for the Commission, and once the risk happens it is easy to withdraw, to avoid larger loss. So it is effective to reduce the risk. In general, the operation efficiency of the logistics enterprises of a certain size is higher than that of non logistics enterprises. Two industries linkage and logistics outsourcing can make the client to maintain a high degree of flexibility, and accelerate the response speed to market, so its professional logistics operations can improve the overall operational efficiency and service quality.

For logistics providers, the linkage development of two industries and logistics outsourcing will undoubtedly increase the volume of business, then help logistics enterprises to increase investment, expand the scale, improve the overall service level.

But the goals of the two are not the same. Generally speaking, the main purpose of enterprise logistics outsourcing is to save the cost. Enterprises separately account for and compare the logistics cost in outsourcing to it in private mode of the. Enterprises choose outsourcing because its cost is lower than the cost in Self-supporting model, while other objective is relatively fuzzy.

By contrast, the objective of linkage development is multiple. On the one hand, manufacturing and logistics industries make contract and regulations, share resource and realize Cooperative operation based on common interests, in order to improve the operation of the whole supply chain level. The two industry linkage development not only means the business to realize linkage, but also to realize linkage in network, organization, operation, benefits and technology. On the other hand, the objective of linkage development tends to the macroscopic overall, and the exploration of linkage development cannot do without the big environment of social development. Manufacture and logistics services respectively belong to the second industry and the third industry, which can't be separated in the new road to industrialization. They are factors of production and service object for each other, and they promote each other, developing together.[6] The linkage development of two industries can not only promote the development of manufacturing and logistics industry, and it's the important way to adjust the industrial structure and change the mode of economic growth. Logistics industry is a service industry to the 9 major industries, the introduction of the restructuring plan will promote the logistics industry upgrading and developing, and the implementation of revitalization plan of other 9 industries. [7]Finally, two industry linkage can promote the coordinated development of regional economy, the equilibrium distribution of the industry, population, resources and environment in the space, so as to enhance the ability of economy and society sustainable development, having a protective effect on the resources and ecological environment. For example, influenced by the international financial crisis, China's auto growth from 2008 began to decline, and the automobile industry suffered a setback. In 2009, under a series of positive measures and "logistics adjustment and revitalization planning", a number of specialized third party logistics enterprises which make Chongqing Changan Minsheng logistics and Fengshen logistics as center sprang up. These third party logistics enterprises formed diversification, personalized development with automobile manufacturing enterprises, from vehicle logistics cooperation first to complete parts admission, supply chain management, import and export of all links linkage. The way of linkage development was different, but they both promoted automobile manufacturing industry and the logistics enterprise developing rapidly. So that the automobile manufacturing industry got through the crisis, and it stimulated the logistics demand in China, promoted the development of the logistics industry.

\section{Requirements}

Whether the enterprise logistics outsourcing or the two industry linkage relates to not one enterprise, but enterprises cooperation, so it requires smooth communication channels, transfer logistics demand information smoothly. The premise is that the logistics cost in cooperation is lower 
than it in self-conducting logistics mode. They both require reasonable selection and supervision to logistics service suppliers, cost control, logistics service quality evaluation and information feedback effectively in order to evade the risk, market risk and management risk.

But the enterprise logistics outsourcing only come down to two enterprises of logistics service demand and supply side, and even sometimes just a one-time cooperation, so its requirements are relatively low. In addition to the above requirements, logistics service providers as long as understand logistics demand of the consignor and rationally plan to provide the appropriate logistics service. While the client as long as choose logistics service providers that can reach its requirement in enterprise scale, reputation and the degree of automation equipment, and provide logistics demand information accurate to the logistics service providers. Enterprises logistics outsourcing have nearly no requirements to other enterprises in the supply chain.

In contrast, two industry linkage development is win-win strategic cooperative relation formed under the background of supply chain, rather than pure competition. Cooperation between two linkage enterprises affect the efficiency of entire supply chain, so the two industry linkage requires higher to linkage manufacturing enterprises ,logistics enterprises, and other enterprises in the supply chain node, to the industry association and to the government. First of all, aiming at the self-run logistics mode in most manufacturing industry, linkage development requires manufacturing industry to change the backward concept of logistics, strip logistics links out, full release logistics demand, trust partner. Secondly, logistics volume in manufacturing enterprises, especially industrial manufacturing enterprises is larger, so demand to logistics enterprises is high. Logistics enterprises should gradually change its present backward situation, and introduce advanced equipment and improve value-added service ability. Thirdly, Information exchange platform linked supply chain must be built smoothly, so that enterprises in the supply chain nodes can share resources, fully trust partners, communicate smoothly. Logistics enterprises should fully understand manufacturing enterprises' demand for logistic, understand the whole supply chain value, in order to provide logistics solutions matching manufacturing enterprises and supply chain. Last the two industry linkage development put forward the request to the macro environment. The government should really implement encourage preferential policies for linkage, reduce policy obstacles, organizations need to play the role of bridge and link, and actively build a platform for communication, promote the logistics standard forming, cultivate talents, provide the basis for the linkage development.

\section{Mutual Relationship}

There are multiple modes in two industry linkage development. Manufacturing enterprises can outsource part of logistics business based on integration of logistics management functions and infrastructure. They also can outsource logistics business without integration. They can set up independent subsidiary logistics corporation, peel logistics department off from enterprises. They also can build third logistics enterprises together with logistics enterprises, [8] and providing logistics services matching manufacturing enterprise custom and mode. Such as the equality and symbiosis mode, relying on the symbiosis mode, embedded accrete mode, complementary symbiosis model and auxiliary exogenous mode. Auxiliary exogenous model means that the logistics enterprises and manufacturing enterprises have a relation of auxiliary service, and manufacturing enterprises will separate and outsource the non-core business to logistics enterprises to realize great logistics. [9]Actually outsourcing logistics can be regarded as a kind of auxiliary exogenous mode. In addition, some people propose that there are many other cluster linkage development models, such as the logistics strategic alliances mode, logistics deposit mode, joint capital development mode and compositive outsourcing development mode. [10]So we can say logistics outsourcing is one of linkage development modes.

China National Offshore Oil Corporation according to the actual requirement, take the self-run logistics and the third party logistics companies combined model. CNOOC and China shipping, COSCO Group have set up a joint venture third party logistics company to undertake the domestic crude oil and natural gas logistics, reducing the logistics cost of CNOOC, improving the operation 
efficiency greatly and sharing the risk and benefit, thus, the linked enterprises truly become a common strategic interest community. From this example we can find out, CNOOC commodities logistics business to the third party, however, the third party logistics company is determined by its internal and external enterprises joint venture, so it is not a simple model of logistics outsourcing, but a kind mode refers to the joint venture linkage model belongs to complementary symbiosis cooperation mode of manufacturing industry and logistics industry linkage development.

\section{Research Content}

The research of linkage and logistics outsourcing refers to the third party logistics enterprises, and the study focused on the necessity, current situation, problems and countermeasures.

The concept of enterprise logistics outsourcing was proposed earlier, so research literature are more, in addition to address these issues, including research on choice of decision-making, research on risk, research on the relationship, research on choosing suppliers, and research on strategy. The research content basically is in the micro level, research object may be a kind of enterprise, such as the production enterprises, sales enterprises, enterprises of science and technology, military enterprises, but not limited to manufacturing enterprises. In addition, there are also some researches with a certain enterprise as the research object. In short, the enterprise logistics outsourcing involves a variety of industries and enterprises, and most of the researches are based on the microscopic study.

The linkage development was proposed late, so researches are still relatively less, and focus on necessity, significance, obstacles and the countermeasures. The research content is in both micro and macro, but the researches on necessity and significance most refer to the whole society or a region macro economy. For example, Chai Guojun (2012) [11] researched the linkage relationship between Inner Mongolia manufacturing industry and modern logistics industry by quantitative analysis method, and analyzes current situation of Mongolia's linkage development. Last he put forward some suggestions on how to promote the interactive development of Inner Mongolia manufacturing industry and modern logistics industry. In terms of research subjects, the research object of two industry linkage only relates to manufacturing enterprises, especially industrial manufacturing enterprises, not include sales, service and other types of enterprises.

\section{Summary}

Although the linkage development of two industries and the enterprise logistics outsourcing have many similarities, the two also have their own characteristics. We can't simply understand linkage development as the enterprise logistics outsourcing. Logistics outsourcing is one of a variety of patterns of two industry linkage development, and in addition to outsourcing, manufacturing enterprises can also choose other linkage operation mode. The concept of enterprise logistics outsourcing was proposed earlier than the linkage development of two industries, so it has more research literature, but from a macro point of view, linkage of two industries contributes to the adjustment of the macro economic structure, so the government encouraging policy on the linkage development are more. At present the linkage development of the two industries is faced with some obstacles, but we all believe that they will be gradually solved through the government, society and enterprises to work together, and we will create a new situation in the two industry linkage development.

\section{Reference}

[1]Huang Youfang. The development trend and suggestions of logistics outsourcing industry in two linkage [J]. Logistics and Material Handling, 2010, (3):59-62 (in Chinese)

[2] Sixth China logistics Supply and demand situation survey report[J]. Logistics and Material Handling, 2005, (11):41-47 (in Chinese)

[3]Wangzuo. The origin and innovation of manufacturing and logistics [J].China business and 
market,2009(2):16-19 (in Chinese)

[4] Circular of the State Council issued on the logistics industry revitalization planning and adjustment[EB/OL]. 2009-03-19 (in Chinese)

[5] Li bingqi.Enhance the level of two industry linkage logistics outsourcing crack problem[J]. Chinese Journal of transportation, 2011,(6):39-41 (in Chinese )

[6]Pang wenying. Linkage development of China's manufacturing and logistics industry. [J] Storage;Transportation \& Preservation of Commodi , 2009,(11):31-35 (in Chinese)

[7] Wangjian, Liudan, Weichongde. Theory and practice of linkage development of manufacturing and logistics industry [M]. 2010, 12 (in Chinese)

[8]Wuqun. Study on the mode and Countermeasures of symbiosis of manufacturing and logistics [J]. Inquiry into Economic Issues ,2011, (1):72-75 (in Chinese)

[9]Hong yitian. Mode of development of the logistics industry and manufacturing cluster linkage [J]. Journal of Liaoning Technical University, 2012, 14(5):477-480. （in Chinese )

[10]Chai guojun,Li wenhao, Wei jingguo et al.research on linkage development of Inner Mongolia manufacturing industry and modern logistics industry [J]. Logistics Sci-Tech, 2012(6)34-37 